\title{
Limitation of enzymatic models for predicting myocardial infarct size
}

\author{
K THYGESEN, M HØRDER, P HYLTOFT PETERSEN, B LYAGER NIELSEN \\ From the Departments of Cardiology and Clinical Chemistry, Odense University Hospital, Odense, Denmark
}

SUMMARY The possibility of predicting myocardial infarct size from early enzyme measurements was studied using a physiological two compartment distribution model. Based on this the time dependent appearance function in plasma was calculated for creatine kinase, aspartate aminotransferase, and lactate dehydrogenase in 29 patients suffering from acute myocardial infarction. On average, the appearance function of the three enzymes started four hours after the onset of symptoms, and the maximum was reached after 12 hours for creatine kinase, 13 hours for aspartate aminotransferase, and 22 hours for lactate dehydrogenase. The cumulated appearance function was used as an acceptable estimate of infarct size. The prediction of infarct size from defined points of the appearance function curve for each of the three enzymes was attempted according to a set schedule during the first 25 hours after the onset of myocardial infarction. The prediction using creatine kinase was superior to the other enzymes. Even so, a reliable prediction could only be established at the very earliest from nine hours and this is too late, as irreversible loss of myocardium occurs rapidly after the onset of symptoms. This, together with the fact that other models have unacceptable variability of the prediction, lead to the onclusion that enzymatic predictive models are of no practical value in clinical intervention studies to reduce infarct size.

Controlled clinical trials designed to evaluate the influence of pharmacological agents on myocardial infarct size can be carried out either after randomised allocation of patients to two or several groups, or the patients can be used as their own controls. Should the first principle be employed a large number of patients is necessary in each group, requiring in actual practice multicentre trials, because of the pronounced interpatient variability of the evolution and size of the infarction. ${ }^{1}$

Alternatively, the patient may be used as his own control, which in theory would reduce the number of patients required in clinical investigations. This has been used in various ways, and one is the method of prediction, ${ }^{23}$ the principle of which is prediction of infarct size from very early changes in an indicator of myocardial damage. A prerequisite is that the prediction can be achieved so early that the modified and the predicted infarct size can be compared in the individual patient. Shell and collaborators ${ }^{2}$ suggested a one compartment predictive enzymatic model requiring the collection of plasma enzyme values during the

Accepted for publication 12 April 1983 first seven hours. This model has been the object of criticism because it is an oversimplification of a highly complex biological system and because of the effects of the great variation in the model variables. ${ }^{4-8}$

Recently we have devised a new more physiological two compartment distribution model ${ }^{9}$ which forms the basis for the calculation of the appearance function for the enzymes: creatine kinase (CK), aspartate aminotransferase (AST), and lactate dehydrogenase (LD). Using this model the object of the present study has been to determine how early after the onset of infarction it is possible to obtain a reliable prediction of infarct size.

\section{Patients and methods}

The investigation included 29 patients with acute myocardial infarction admitted to the coronary care unit on average 112 minutes (range 25 to $280 \mathrm{~min}$ ) after the onset of retrosternal pain of more than 20 minutes duration. This and daily routine recordings of a 12 lead electrocardiogram and a diagnostic rise in the daily determination of serum enzymes (CK, AST, and LD) were used in establishing a definite diagnosis of acute myocardial infarction. ${ }^{10}$ The average age of 
the patients was 63 years (range 44 to 80); 20 men and nine women. They were treated according to the usual procedure, that is rest in bed, morphine, antiarrhythmic drugs, diuretics as required, and oxygen via a nasal catheter when necessary.

Blood for measurement of total CK, total AST, and total $L D$ was sampled on admission and every three to four hours throughout $\mathbf{4 8}$ hours, and then three to four times daily for approximately one week ${ }^{8}$ Catalytic activity in plasma of CK (EC 2.7.3.2), AST (EC 2.6.1.1), and LD (EC 1.1.1.27) was determined according to the Nordic recommended methods. ${ }^{11} 12$

The calculation of the appearance function, which is the time dependent influx of new enzymes into plasma, was based on a two compartment model (Fig. 1). The appearance function was calculated for each time interval between two consecutive blood samples by simultaneous solution of mathematical equations for the differential changes in amount of enzyme in plasma and extravascular space, respectively, and the values of exchange rate constants for enzymes between the compartments were chosen from rate constants for proteins with molecular weights similar to those of the three enzymes. ${ }^{9}$ Based on this, plasma enzyme activities were transformed to enzyme appearance function without assumptions as to the shape of these curves (that is no curve fitting technique is applied). The characteristics of the appearance function curve are shown in Fig. 2. The $10 \%$ level of the maximum of the appearance function is depicted on the curve. This is used as an estimation of the biological background noise of the enzymes. The cumulated appearance function (not shown in Fig. 2) is used as an index of infarct size.

\section{STATISTICAL ANALYSIS}

Differences between groups and times were evaluated using a two way analysis of variance. Additional differences in times were evaluated by means of an

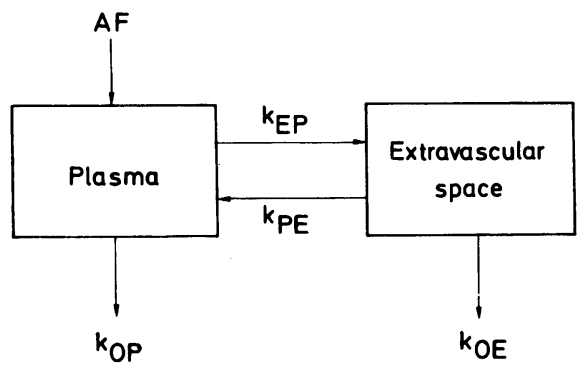

Fig. 1 The two compartment model for the turnover of ensymes between plasma and extravascular space. $A F$, appearance function, $k_{E P}$ and $k_{P E}$, rate constants for exchange of enzymes between the two compartments. $k_{O P}$ and $k_{O E}$, rate constants for katabolism in plasma and extravascular space, respectively.

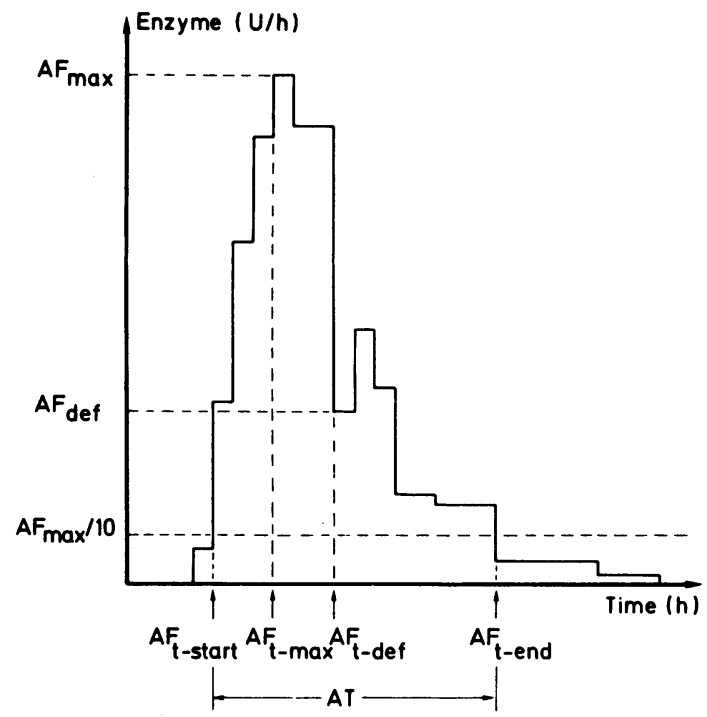

Fig. 2 Characteristics of appearance function for enzymes in plasma according to a two compartment model. The maximum of the appearance function $\left(A F_{\max }\right)$ and its occurrence from onset of chest pain $\left(A F_{t-\max }\right)$ are shown. The start and the end of the appearance function $\left(A F_{t-s t a n}\right.$ and $\left.A F_{\text {tend }}\right)$ are the times at which the appearance function exceeds or goes below, respectively, the level of $10 \%$ of the maximum of the appearance function $\left(A F_{\max } / 10\right)$. The period of appearance $(A T)$ is the difference between the end and the start of the appearance function $\left(A F_{\text {tend }}-A F_{t-\text { stan }}\right)$. Finally, defined point of the appearance function ( $\left.A F_{\text {def }}\right)$ and time for its occurrence $\left(A F_{t \text {-def }}\right)$ are shown on the curve.

unpaired $\mathrm{t}$ test. Analysis of correlation was used for calculation of the coefficient of correlation ( $r$ ) and coefficient of determination $\left(r^{2}\right)$. Comparison of $r$ values was performed using Fisher's z-transformation of r. ${ }^{13}$ A significance level of 0.05 was selected.

\section{Results}

Table 1 shows the characteristic times of the appearance function for CK, AST, and LD. The start of the appearance function occurred, on average, four hours after the onset of symptoms and there was no significant difference between the three enzymes.

The maximum of the appearance function occurred, on average, after 12 hours for CK, after 13 hours for AST, and after 22 hours for LD; these were significantly different. This difference was due to $L D$, as there was no significant difference between $\mathrm{CK}$ and AST. Similarly, the period of appearance of the three enzymes showed a significant difference, again because of $\mathrm{LD}$.

The cumulated appearance function of the three enzymes was mutually correlated, as shown in Table 2. 
Table 1 Characteristic times (mean and range in hours) of appearance function of enrymes in plasma in acute myocardial infarction $(n=29)$

\begin{tabular}{|c|c|c|c|c|c|c|}
\hline & \multicolumn{2}{|c|}{ Start of appearance function* $(h)$} & \multicolumn{2}{|c|}{ Maximum of appearance function ${ }^{\star}(h)$} & \multicolumn{2}{|c|}{ Period of appearance* $(h)$} \\
\hline & Mean & Range & Mean & Range & Mean & Range \\
\hline $\begin{array}{l}\text { CK } \\
\text { AST } \\
\text { LD }\end{array}$ & $\begin{array}{l}4 \cdot 0 \\
3.6 \\
3 \cdot 8 \\
\end{array}$ & $\begin{array}{l}1 \cdot 5-9 \\
1 \cdot 5-10 \\
1 \cdot 2-14\end{array}$ & $\begin{array}{l}12 \\
13 \\
22\end{array}$ & $\begin{array}{l}2 \cdot 0-24 \\
2 \cdot 0-35 \\
4 \cdot 9-42\end{array}$ & $\begin{array}{l}33 \\
36 \\
45\end{array}$ & $\begin{array}{l}11-74 \\
11-79 \\
11-134\end{array}$ \\
\hline
\end{tabular}

^For definitions see legend to Fig. 2.

Table 2 Interrelation of cumulated appearance functions of $C K, A S T$, and $L D(n=29)$

\begin{tabular}{lll}
\hline Enryme correlation & \multicolumn{2}{l}{ Cumulated appearance function } \\
\cline { 2 - 3 } & $r$ & $p$ \\
\hline CK and AST & 0.92 & $<0.001$ \\
CK and LD & 0.81 & $<0.001$ \\
AST and LD & 0.83 & $<0.001$ \\
\hline
\end{tabular}

The three $r$ values $(0.92,0.81,0.83)$ were not significantly different.

As expected, the maximum of the appearance function of all three enzymes was significantly positively correlated to the respective cumulated appearance function, as shown in Table 3. The coefficients of determination, however, were rather low in respect of $\operatorname{AST}\left(r^{2}=0.59\right)$ and $\operatorname{LD}\left(r^{2}=0.40\right)$.

In order to predict the cumulated appearance function during the early phase of myocardial infarction
Table 3 Coefficient of correlation between maximum and cumulated appearance function for $C K, A S T$, and $L D(r)$, as well as coefficient of determination $\left(r^{2}\right)(n=29)$

\begin{tabular}{llll}
\hline Ensyme & $r$ & $p$ & $r^{2}$ \\
\hline CK & 0.87 & $<0.001$ & 0.76 \\
AST & 0.77 & $<0.001$ & 0.59 \\
LD & 0.63 & $<0.001$ & 0.40 \\
\hline
\end{tabular}

various defined points of the appearance function curve were correlated to the respective cumulated appearance function during the first 25 hours after the onset of symptoms; Fig. 3 shows these $r$ values plotted as a function of time, as well as the $r$ values between the maximum and cumulated appearance function for all three enzymes.

In respect of $\mathrm{CK}$, a comparison of $\mathrm{r}$ values between the maximum and cumulated appearance function $(r=0.87)$ and between defined points and cumulated

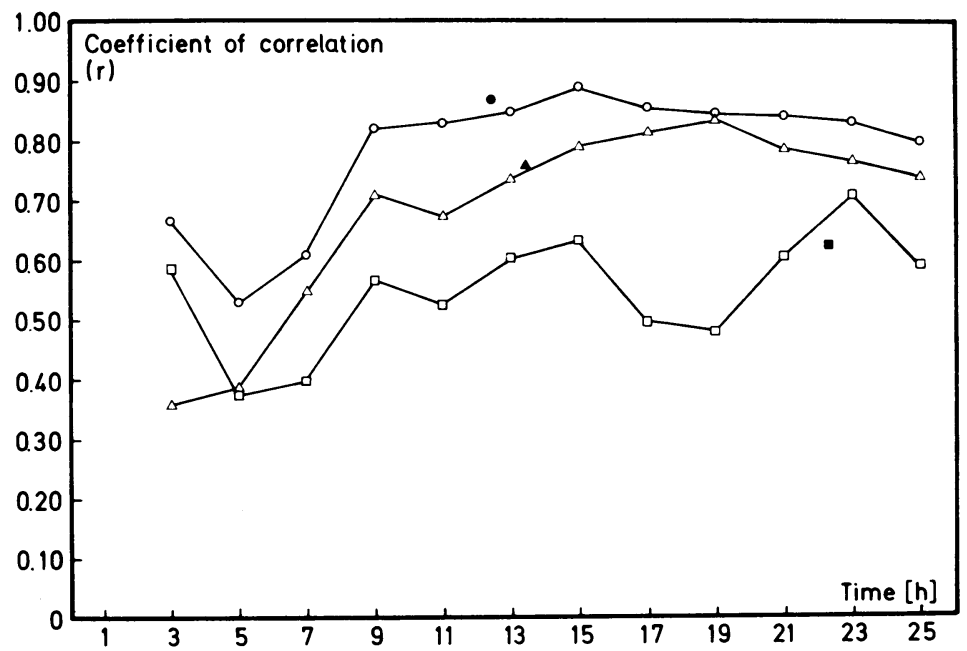

Fig. 3 Correlation coefficients between defined points of the appearance function curve and the cumulated appearance function as well as between the maximum and cumulated appearance function for $C K, A S T$, and $L D$, plotted as a function of time. Open circles, open triangles, and open squares $=r$ values between defined points and cumulated appearance function for $C K, A S T$, and $L D$, respectively. Filled circle, filled triangle, and filled square $=r$ values between maximum and cumulated appearance function for $C K, A S T$, and $L D$, respectively. 
appearance function showed that the latter values were significantly lower at times three, five, and seven hours, whereas there was no significant difference within hours nine to 25 .

At all times the $r$ values for $C K$ were higher than the corresponding values for the other two enzymes; a significant difference could be shown between $\mathrm{CK}$ and $\operatorname{LD}(\mathrm{p}<0.05)$.

\section{Discussion}

The size of an acute myocardial infarction has been estimated from plasma time-activity curves using models attributing serial changes in plasma enzyme activity to release from the heart and concomitant disappearance from the circulation. ${ }^{14-18}$ These models are, in principle, based on the assumption of a one compartment distribution space; criticism, however, has been raised against these as they are very sensitive to variations in the variables used and simplify an extremely elaborate system..$^{458}$ As several proteins, including enzymes, are present in both extravascular and intravascular pools it has been suggested that multicompartment models should be used, which, from a physiological point of view, should provide a more valid evaluation of the extent of enzyme release from infarcted heart muscle. ${ }^{91920}$ It has been pointed out, however, that for the purpose of calculation, a number of extravascular spaces may be lumped together into a single extravascular compartment. ${ }^{21}$ Thus, a two compartment model is preferable to a one compartment model for describing the distribution of enzymes. 9

Our results indicate that the leakage of enzymes from heart cells starts early after the infarction. Thus, the time dependent influx of new enzymes into plasma took place in some patients a little more than one hour after the onset of symptoms, and, on average, after four hours for the enzymes investigated in this study. Probably because of an increase in cell membrane permeability, ${ }^{19}$ the appearance rate rises progressively and reaches a maximum, on average, after 12 hours for CK, after 13 hours for AST, and 22 hours for LD.

When using the cumulated appearance function as an estimate of infarct size, the present study shows that the three enzymes are equally applicable. This is based on the fact that there was no significant difference between the coefficients of correlation of the cumulated appearance functions when studying the interrelation of CK, AST, and LD.

It has been suggested that the maximum activity of enzymes in plasma gives a reasonably good clinical estimate of infarct size ${ }^{78}$ because there is a close correlation between maximum $\mathrm{CK}$ values and calculated infarct size, both in a one compartment and a two compartment model $(r=0.93$ and 0.91 , respec- tively). ${ }^{822}$ We have also found a high coefficient of correlation $(r=0.87)$ between the maximum of the appearance function and the calculated infarct size in respect of CK. The corresponding correlation of AST and $L D$ were poorer and in our opinion unacceptable as the coefficients of determination $\left(r^{2}\right)$ were only 0.59 and 0.4 , respectively. This means that a variation of the maximum appearance function can explain $59 \%$ of the variation of the calculated infarct size when using AST and $40 \%$ in the case of LD. The observation that the maximum of the appearance function of $\mathrm{CK}$ is a good estimator of infarct size can be used in clinical trials with between-patient study design.

The feasibility of predicting infarct size from plasma enzyme activities in the very early phase of myocardial infarction has attracted considerable interest. In 1973, Shell and coworkers designed a curve fitting technique for this purpose and used data obtained during the first hours after the initial CK rise to predict the most likely course of the entire curve. In order to estimate the expected infarct size, both the predicted and observed values were analysed using the same one compartment model. ${ }^{2}$ Various modifications and improvements have been suggested in the original predictive algorithm, ${ }^{17} 1823$ but none has been able to overcome the main objection, that even small "noise" in the collected data results in such variability in predicted infarct size that the usefulness of the method has been seriously questioned..$^{4-7}$

Infarct size can be estimated and consequently predicted with reasonable reliability when the maximum appearance rate of $\mathrm{CK}$ occurs, that is, at 12 hours. Irreversible loss of myocardium, however, takes place so rapidly after onset of symptoms that intervention must be carried out during the first four to six hours 2425 in order to have the greatest beneficial effect. Thus, it is obvious that prediction must be performed even earlier, and the time for maximum appearance function of $\mathrm{CK}$ is too late in this respect. Therefore, predictors appearing earlier than the maximum appearance function and having the same validity have been sought in the present investigation. This has shown that reliable prediction can only be established from nine hours despite the use of a more physiological two compartment distribution model.

In general, these findings clearly show that enzymatic predictive models for infarct sizing are too unreliable and cannot be used early enough after the onset of infarction for the patient to act as his own control in clinical intervention studies.

\section{References}

1 Thygesen K. Assessing acute myocardial infarction by electrocardiography. Odense: Odense University Press, 1981. 
2 Shell WE, Lavelle JF, Covell JW, Sobel BE. Early estimation of myocardial damage in conscious dogs and patients with evolving acute myocardial infarction. $f$ Clin Invest 1973; 52: 2579-90.

3 Askenazi J, Maroko PR, Lesch M, Braunwald E. Usefulness of ST segment elevations as predictors of electrocardiographic signs of necrosis in patients with acute myocardial infarction. Br Heart $\mathcal{F}$ 1977; 39: 764-70.

4 Roe CR, Starmer CF. A sensitivity analysis of enzymatic estimation of infarct size. Circulation 1975; 52: 1-5.

5 Roe CR. Validity of estimating myocardial infarct size from serial measurements of enzyme activity in the serum. Clin Chem 1977; 23: 1807-12.

6 Danner SA, Smit EM, Hart GAM, Oosting H, Dunning AJ. Prediction of infarct size from serial CK determinations: evaluation by clinical studies and computer simulation. Clin Chim Acta 1979; 97: 45-57.

7 Ryan W, Karliner JS, Gilpin EA, Covell JW, DeLuca $M$, Ross J Jr. The creatine kinase curve area and peak creatine kinase after acute myocardial infarction: usefulness and limitations. Am Heart $\mathcal{f}$ 1981; 101: 162-8.

8 Horder M, Petersen PH, Thygesen K, Nielsen BL. Plasma enzymes in myocardial infarction. An appraisal of quantitative, clinical and pathophysiological information. Scand $\mathcal{F}$ Clin Lab Invest 1981; 41: 41-7.

9 Petersen PH, Horder M, Thygesen K, Nielsen BL, Hansen L. Plasma enzymes in myocardial infarction. Application of a two-compartment model in assessing myocardial release of enzyme. Scand f Clin Lab Invest 1981; 41: $735-41$.

10 World Health Organization. Report of the fifth working group on the establishment of ischaemic heart disease registers. Copenhagen: WHO regional office for Europe, 1971.

11 The committee on enzymes of the Scandinavian Society for Clinical Chemistry and Clinical Physiology. Recommended methods for the determination of four enzymes in blood. Scand F Clin Lab Invest 1974; 33: 291-306.

12 Horder M, Magid E, Pitkänen E, et al. Recommended method for the determination of creatine kinase in blood modified by the inclusion of EDTA. Scand $\mathcal{f}$ Clin Lab Invest 1979; 39: 1-5.

13 Snedecor GW, Cochran WG. Statistical methods. 6th ed. Ames, Iowa: The Iowa State University Press, 1967.

14 Shell WE, Kjekshus JK, Sobel BE. Quantitative assessment of the extent of myocardial infarction in the con- scious dog by means of analysis of serial changes in serum creatine phosphokinase activity. $\mathcal{f}$ Clin Invest 1971; 50: 2614-25.

15 Sobel BE, Shell WE. Serum enzyme determinations in the diagnosis and assessment of myocardial infarction. Circulation 1972; 45: 471-82.

16 Mathey D, Bleifeld W, Hanrath P, Effert S. Attempt to quantitate relation between cardiac function and infarct size in acute myocardial infarction. Br Heart $\mathcal{f} 1974$; 36: 271-9.

17 Norris RM, Whitlock RML, Barratt-Boyes C, Small CW. Clinical measurement of myocardial infarct size. Modification of a method for the estimation of total creatine phosphokinase release after myocardial infarction. Circulation 1975; 51: 614-20.

18 Roberts R, Henry PD, Sobel BE. An improved basis for enzymatic estimation of infarct size. Circulation 1975; 52: 743-54.

19 Witteveen SAGJ, Hemker HC, Hollaar L, Hermens WT. Quantitation of infarct size in man by means of plasma enzyme levels. Br Heart $\mathcal{f}$ 1975; 37: 795-803.

20 Sobel BE, Markham J, Karlsberg RP, Roberts R. The nature of disappearance of creatine kinase from the circulation and its influence on enzymatic estimation of infarct size. Circ Res 1977; 41: 836-44.

21 Nosslin B. Analysis of disappearance time-curves after single injection of labelled proteins. In: Wolstenholme GEW, O'Connor M, eds. Protein turnover. Ciba Foundation Symposium 9. Amsterdam: Elsevier/Excerpta Medica/North-Holland, 1973: 113-30.

22 Hermens WT, Witteveen SAGJ. Problems in estimation of enzymatic infarct size. $\mathcal{F ~ M o l ~ M e d ~ 1 9 7 7 ; ~ 2 : ~ 2 3 3 - 9 . ~}$

23 Tommasini G, Presta $M$. Prediction of infarct size by enzymatic techniques: modification of a method and clinical application. Br Heart $\mathcal{F} 1979$; 42: 326-32.

24 Selwyn AP, Ogunro E, Shillingford JP. Loss of electrically active myocardium during anterior infarction in man. Br Heart F 1977; 39: 1186-91.

25 Swan HJC, Shah PK, Rubin S. Role of vasodilators in the changing phases of acute myocardial infarction. $\mathrm{Am}$ Heart f 1982; 103: 707-15.

Requests for reprints to Dr K Thygesen, Department of Cardiology, Aarhus University Hospital, DK-8000 Aarhus C, Denmark. 